\title{
Computed tomography of the brain in kwashiorkor: a follow up study
}

\author{
K C Househam
}

\begin{abstract}
Computed tomography of the brain was performed initially and after nutritional rehabilitation on 12 children with kwashiorkor. The severe cerebral shrinkage evident initially resolved after nutritional rehabilitation. The mechanism and significance of this reversible abnormality remains to be determined.
\end{abstract}

The effect of severe protein energy malnutrition on the developing brain remains a controversial issue. In a previous report the presence of cerebral atrophy or brain shrinkage in eight children with kwashiorkor was described. ${ }^{1}$ The precise nature of the loss of brain volume was uncertain. To determine the implications of these findings a follow up study was undertaken.

\section{Patients and methods}

Twelve children aged 11 to 28 months (median $17 \cdot 7$ months) were studied. Seven were girls and all were admitted primarily for management of severe protein energy malnutrition. One child had significant gastroenteritis that required rehydration and correction of a metabolic acidosis.

On inclusion into the study the children were assessed clinically and by means of computed tomography of the brain. All subjects were norof the computed tomography. The scans were carried out two to three weeks after admission. The tomograms of the brain were performed trast.

Consent was obtained from the parents in each case. The study was approved by the ethical committee of the Medical Faculty of the University of the Orange Free State.

The children were discharged for further nutritional rehabilitation at home. They were followed up and re-evaluated on average 14 months after the initial assessment.

Department of Paediatrics and Child Health, Faculty of Medicine, University of the Orange Free State, PO Box 339 (G69) Bloemfontein 9300 Republic of South Africa

Correspondence to: Professor Househt

Accepted 5 November 1990 were less than $60 \%$ of expected weights for age, indicating severe malnutrition or marasmic kwashiorkor. The mean expected height for age was $92 \cdot 2 \%$. Head circumference was measured initially in 11 and was normal in seven children. mally hydrated and clinically stable at the time according to standard procedures without con-

Nutritional and growth variables in 12 cases before and after nutritional rehabilitation

\begin{tabular}{|c|c|c|c|c|c|c|}
\hline \multirow[t]{2}{*}{$\begin{array}{l}\text { Case } \\
\text { No }\end{array}$} & \multicolumn{2}{|c|}{$\begin{array}{l}\text { Mass } \\
(\% E W)^{*}\end{array}$} & \multicolumn{2}{|c|}{$\begin{array}{l}\text { Head circumference } \\
\text { (NCHS centile)t }\end{array}$} & \multicolumn{2}{|c|}{$\begin{array}{l}\text { Albumin } \\
(\mathrm{g} / \mathrm{l})\end{array}$} \\
\hline & Before & After & Before & After & Before & After \\
\hline $\begin{array}{r}1 \\
2 \\
3 \\
4 \\
5 \\
6 \\
7 \\
8 \\
9 \\
10 \\
11 \\
12\end{array}$ & $\begin{array}{l}79 \\
63 \\
71 \\
63 \\
71 \\
72 \\
54 \\
80 \\
50 \\
60 \\
87 \\
76\end{array}$ & $\begin{array}{r}90 \\
84 \\
81 \\
86 \\
102 \\
81 \\
83 \\
90 \\
85 \\
92 \\
106 \\
95\end{array}$ & $\begin{array}{l}<3 \\
50 \\
75 \\
<3 \\
25 \\
<3 \\
\text { Missing } \\
60 \\
<3 \\
30 \\
90 \\
25\end{array}$ & $\begin{array}{l}<3 \\
48 \\
60 \\
25 \\
75 \\
25 \\
50 \\
96 \\
38 \\
40 \\
97 \\
50\end{array}$ & $\begin{array}{l}16 \\
16 \\
13 \\
16 \\
14 \\
19 \\
23 \\
24 \\
22 \\
14 \\
15 \\
20\end{array}$ & $\begin{array}{l}36 \\
43 \\
37 \\
46 \\
43 \\
34 \\
43 \\
36 \\
\text { Missing } \\
41 \\
42 \\
38\end{array}$ \\
\hline
\end{tabular}

$\% \mathrm{EW}=$ percentage of expected weight for age

In all patients the head circumference appeared appropriate to the body size.

Serum albumin concentrations were low in all patients (mean $17 \cdot 7 \mathrm{~g} / \mathrm{l}$ ) and in eight were below $20 \mathrm{~g} / \mathrm{l}$. All had clinical features typical of kwashiorkor such as generalised oedema, skin lesions, and hair changes. All were typically apathetic and withdrawn on admission.

The computed tomograms showed cerebral atrophy in all 12 children. In eight there appeared to be a severe degree of atrophy with pronounced enlargement of the ventricles and cerebral sulci. There were no other abnormalities evident on computed tomography.

At restudy after a mean of 14 months (range $9 \cdot 3$ to $24 \cdot 1$ months) the children all were nourished normally with masses and heights greater than $80 \%$ of the expected for age (table). The head circumference was normal in 11 children. In the remaining child the head circumference was just below the third centile when it previously had been far below this centile. The child had no signs of gross neurological deficit. The serum albumin concentrations were normal in 11 children with one value of $34 \mathrm{~g} / 1$ just below normal (mean 39.9, range $34-46 \mathrm{~g} / \mathrm{l}$ ).

The computed tomograms in all children showed dramatic improvement with 11 of the 12 being within the limits of normal. Tomograms before and after nutritional rehabilitation are shown in fig 1 and 2 . In one child the cerebral atrophy had resolved but there was a residual abnormality of the left parietal cortex with widening of the sulci and a loss of cerebral cortex. This was suggestive of an old cerebral infarction (fig 3). The patient had no neurological signs on physical examination.
Discussion

The results of this study demonstrate the dra- 

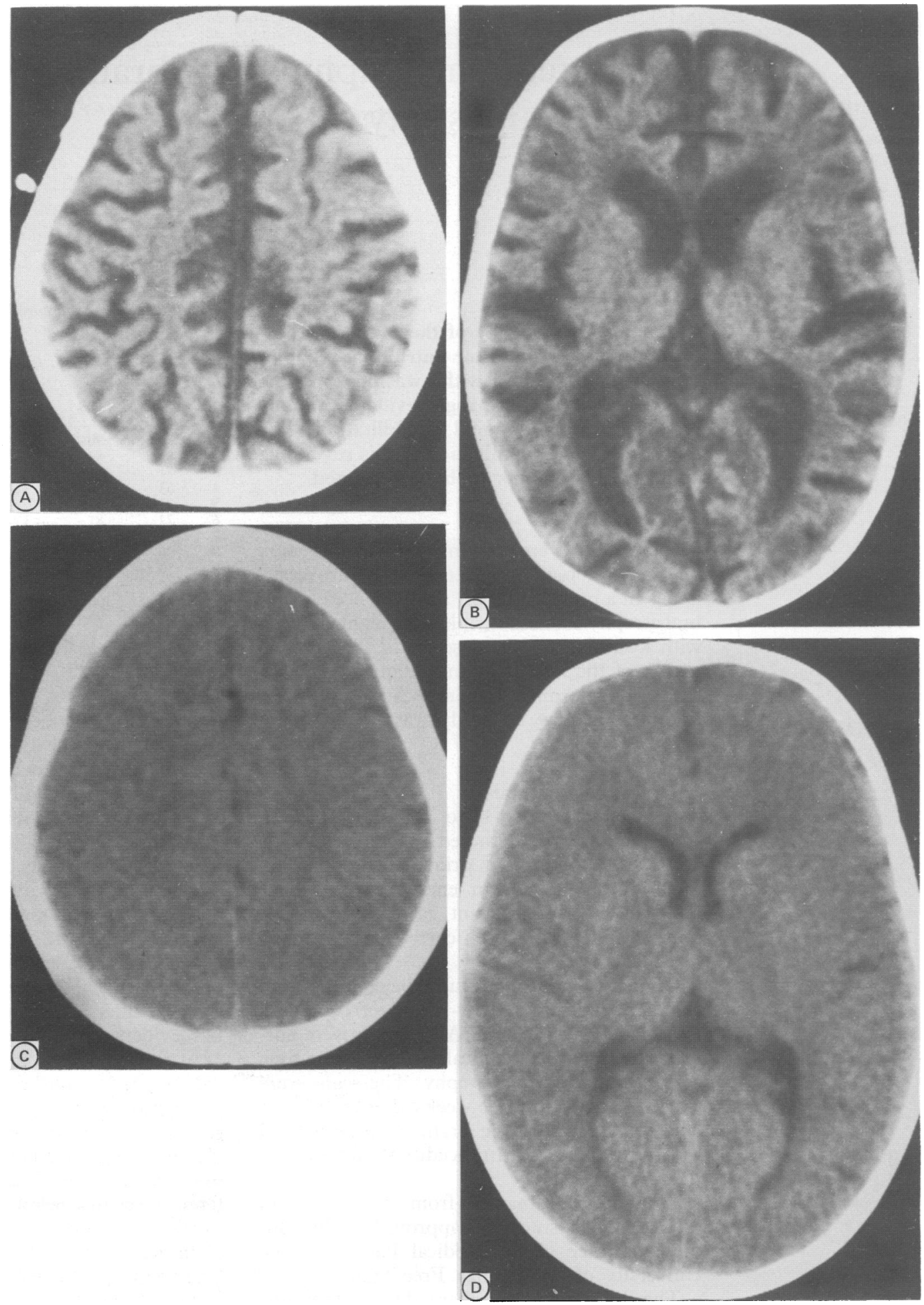

Figure 1 Computed tomograms of case $8(A)$ and $(B)$ showing widened cerebral sulci and enlarged ventricles and $(C)$ and (D) after nutritional rehabilitation for one year showing a normal appearance.

matic resolution of the cerebral shrinkage found in all patients during the acute phase of kwashiorkor, an average of 14 months after the commencement of nutritional rehabilitation. During this time the nutritional state of the children also had improved and they appeared well generally with no sequelae of the preceding episode of severe kwashiorkor.

No definite neuropathology has been associated previously with protein energy malnutrition. In animal studies cell migration and the elaboration of cell processes in the brain are affected negatively. ${ }^{3}$ The cell morphology remains normal but cell numbers in the brain may be decreased. ${ }^{4}$ The glial cells mainly are affected with reduction in the lipid content of the myelin membrane. ${ }^{56}$

Work in animals and observations in humans indicate that severe protein energy malnutrition at a time of rapid brain growth in infancy and early childhood is associated with reduced head size and brain weight. ${ }^{7-9}$ Work done during the 

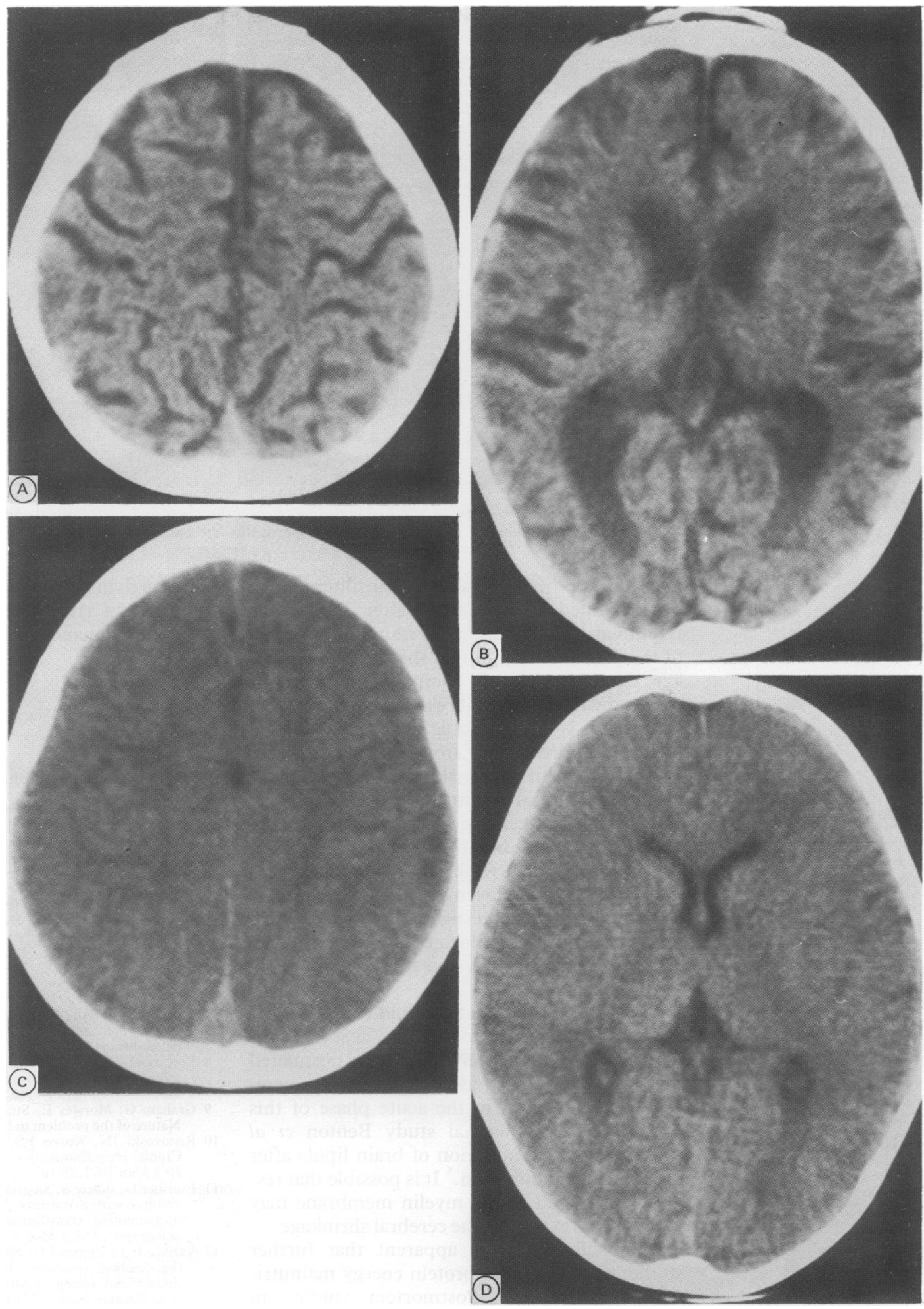

Figure 2 Computed tomograms of case $11(A)$ and $(B)$ showing diffuse cerebral shrinkage and $(C)$ and $(D)$ after nutritional rehabilitation for $14 \cdot 8$ months showing a normal appearance.

early 1970s demonstrated increased transillumination over the cerebrum suggesting shrinkage of the intracranial contents in infants with severe marasmus and kwashiorkor. ${ }^{10} 11$ The cerebrospinal fluid in these children was normal and there was free circulation of the cerebrospinal fluid excluding the possibility of subdural effusions. ${ }^{10}$ It was assumed that the increase in cerebrospinal fluid was relative due to loss of brain substance or cerebral atrophy. Echoencep- halographic studies of Ethiopian children with kwashiorkor produced similar findings. ${ }^{12}$ These studies are in conformity with the cerebral shrinkage or atrophy demonstrated on computed tomography in our studies. The important question concerns the nature of the cerebral shrinkage and whether the changes are reversible.

In a further study of Ethiopian children over the age of 2 years of age with marasmic 

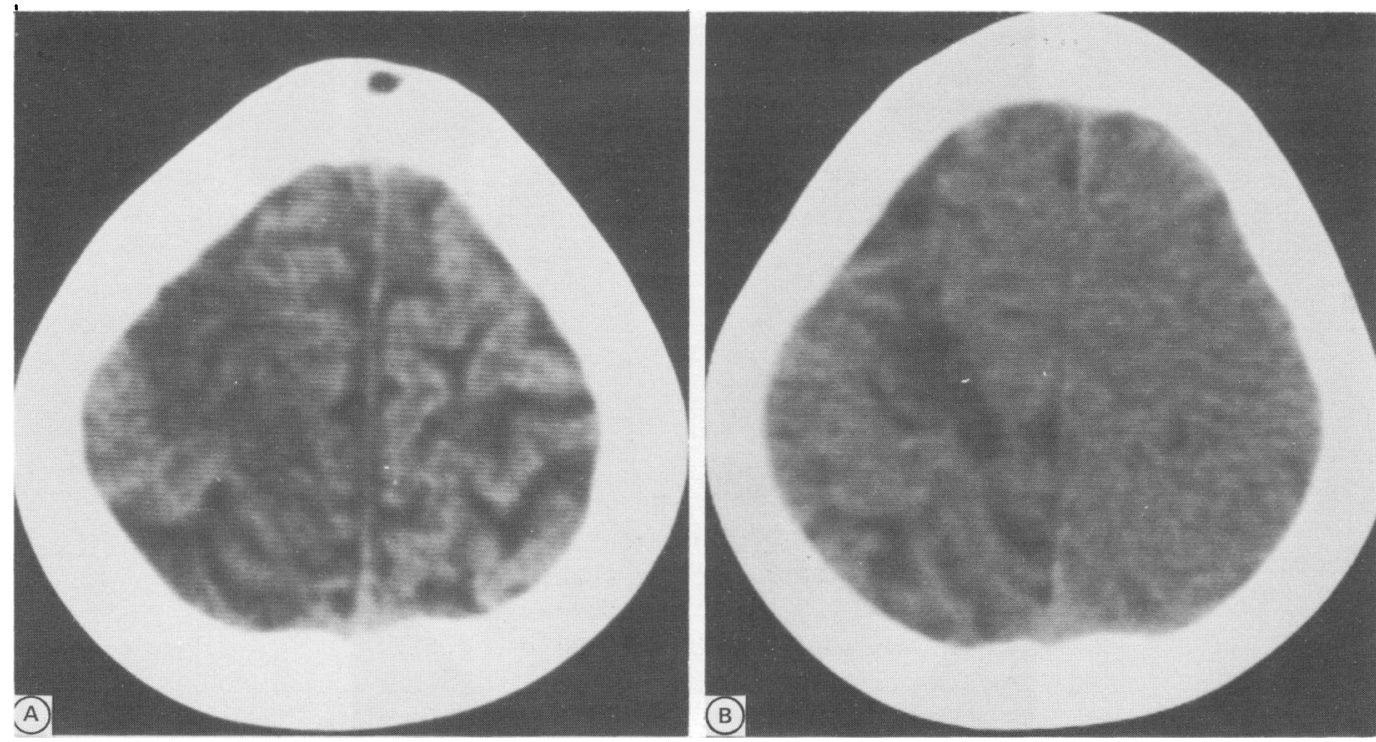

Figure 3 Computed tomogram of case $2(A)$ showing cerebral shrinkage and a left cortical abnormality and $(B)$ after nutritional rehabilitation for 10.6 months with a persisting left cortical abnormality.

kwashiorkor the increased transillumination demonstrated disappeared after nutritional treatment. ${ }^{11}$ This finding corresponds with that of the present study in that the cerebral shrinkage demonstrated on computed tomography resolved with nutritional rehabilitation.

As there is no detectable neurological deficit in these children, apart from apathy and irritability, significant neuronal loss is unlikely. Loss of interstitial fluid is a further possible cause of cerebral shrinkage. As interstitial fluid generally is increased due to a decreased serum oncotic pressure in kwashiorkor, however, this pathogenesis would seem unlikely. It must be stressed that the investigations by computed tomography were performed in patients who were hydrated normally and showed no electrolyte imbalance.

In view of the fact that the lipid content of the brain has been shown to decrease in severe protein energy malnutrition ${ }^{5} 6$ it may be postulated that loss of myelin lipid accounts for the cerebral shrinkage seen in the acute phase of this condition. In an animal study Benton et al demonstrated a restoration of brain lipids after nutritional rehabilitation. ${ }^{5}$ It is possible that restoration of lipid to the myelin membrane may account for reversal of the cerebral shrinkage.

In conclusion, it is apparent that further studies of the brain in protein energy malnutrition are required. Postmortem studies in children dying of acute protein energy malnutrition, and in vivo studies by means of nuclear magnetic resonance, may provide the answer.

1 Househam KC, de Villiers JFK. Computed tomography in severe protein energy malnutrition. Arch Dis Child 1987;62: 589-92.

2 Hamil PVV, Dridzl TA, Johnson CL, et al. Physical growth: National Center for Health Statistics percentiles. A $\mathrm{F}$ F Clin Nutr 1979;32:607-29.

3 Dobbing J, Hopewell JW, Lynch A. Vulnerability of developing brain. VII. Permanent deficit of neurons in developing brain. VII. Permanent deficit of neurons in nutrition. Exp Neurol 1971;32:439-47.

4 Winick M, Rosso P, Waterlow J. Cellular growth of cerebrum, cerebellum and brainstem in normal and marasmic children. Exp Neurol 1970;26:393-400.

5 Benton JW, Moser HW, Dodge PR, Carr S. Modification of the schedule of myelination in the rat by early nutritional deprivation. Pediatrics 1966;38:801-7.

6 Bass NH, Netsky MG, Young E. Microchemical studies o postnatal development of rat cerebrum. II Formation of myelin. Neurology 1969;19:405-14.

7 Stoch MB, Smythe PM. The effect of undernutrition during infancy on subsequent brain growth and intellectual development. S Afr Med f 1967;41:1027-30.

8 Pretorius PJ, Novis H. Nutritional marasmus in Bantu infants in the Pretoria area. II. Clinical and pathological aspects. S Afr Med F 1965;39:501-5.

9 Graham G, Morales E. Studies in infantile malnutrition. I. Nature of the problem in Peru. $\mathcal{F}$ Nutr 1963;79:479-87.

10 Rozovoski JN, Novoa FS, Arbarzua JF, Monckeberg FB. Cranial transillumination in early and severe malnutrition. Br f Nutr 1971;25:107-11.

11 Engsner G, Belete S, Sjogren I, Vahlquist B. Brain growth in children with marasmus. A study using head circumference measurement, transillumination and ultrasonic echo ventriculography. Ups $\mathcal{F}$ Med Sci 1974;79:116-28.

12 Vahlquist B, Engsner G, Sjogren I. Malnutrition and size of the cerebral ventricles. Echoencephalographic studies in infants and young children: preliminary communication. Acta Paediatr Scand 1971;60:533-9. 